\title{
Climate Change Mitigation Through Smart Environmental Monitoring of the Urban Ecosystem in Insular Touristic Cities: Experience from Rethymno and Madeira
}

\author{
Maria Aryblia, Lúcio Quintal, Miguel Ribeiro, Nikolaos Sifakis, \\ Stavroula Tournaki, and Theocharis Tsoutsos
}

\begin{abstract}
Cities, and general urban areas, contribute critically to climate change because of the GHGs related to traffic congestion, fossil fuel consumption, noise and air pollution. Air pollution, despite the noteworthy improvements during the last decades, still plays a significant role in the quality of living in European cities as it causes damages to health and ecosystems, thus making urgent the immoderate need of diminishing it. Within the Horizon 2020 CIVITAS DESTINATIONS project, six European island cities, which are highly attractive destinations for tourists worldwide, implemented various sustainable mobility measures. Among them, Funchal, Madeira-Portugal, and Rethymno, Crete-Greece, implemented two different environmental monitoring systems to measure and calculate a predetermined set of indicators, capable of estimating the environmental benefits in transport, economy, society, energy, and the environment. The monitoring systems were installed in specific sites all around these two cities, aiming, through the integrated sensors, to collect environmental data related to transport load, such as environmental indexes (temperature, humidity, noise) and air pollutants $\left(\mathrm{CO}_{2}, \mathrm{CO}, \mathrm{NO}_{\mathrm{x}}, \mathrm{SO}_{2}, \mathrm{PM}\right)$. The collection of critical and reliable data offers the opportunity for an effective evaluation of the overall performance of the implemented measures toward sustainable, environmentally friendly, and low-carbon mobility policies.
\end{abstract}

Keywords Air quality • Transport impacts • Environmental impact assessment • Environmental monitoring $\cdot$ Urban environment

\footnotetext{
M. Aryblia $\cdot$ N. Sifakis $\cdot$ S. Tournaki $\cdot$ T. Tsoutsos $(\bowtie)$

Renewable and Sustainable Energy Systems Lab, School of Chemical and Environmental Engineering, Technical University of Crete, Chania, Greece

e-mail: theocharis.tsoutsos@enveng.tuc.gr

L. Quintal

Arditi, Funchal, Portugal

M. Ribeiro

Computer Science and Engineering, Técnico Lisboa, Lisboa, Portugal
} 


\section{Introduction}

Although significant changes over the past decades, air pollution remains a source of harm to human health and ecosystems (Park, 2020; Santos, 2017). Road transport, which contributes to a substantial share of Greenhouse Gas (GHG) transport pollution, plays a vital role in this, which significantly impacts air quality in urban spaces with superior road traffic levels (Santos, 2017). Road transport nowadays accounts for more than $82 \%$ of the personal transportation of people, including automobiles, two-wheeled vehicles, and buses/coaches. In comparison, $49 \%$ of freight traffic is road-related. Road transport vehicles often use fossil fuels, which emit large amounts of Greenhouse Gases (GHGs), and something noteworthy is that almost two-thirds of these pollutants come from light-duty automobiles (Bharadwaj et al., 2017; European Commission, 2017).

Road transport is the second-highest energy-consuming industry in Europe, after the industrial sector, and accounts for about $73 \%$ of overall GHG emissions from transport (Letnik et al., 2018). Air pollution often impacts other industries, including human health burdens, such as the industry, when job efficiency decreases under polluted conditions. As a consequence, sustainable mobility has been one of the main drivers for meeting the targets of the Paris Climate Change Agreement commitments. The adverse effects on the climate, energy, health, and economy of contemporary modes of transport have contributed to policies encouraging a sustainable future, which means cleaner, more secure, and more efficient mobility. In terms of fuel use, congestion, air and noise pollution, sustainability, connectivity, and quality of life, European cities face critical challenges (Andrés \& Padilla, 2018; Santos, 2017).

It has also been shown that the environmental impacts of air pollution have a direct relationship with some severe health problems and are a vital risk factor for premature mortality (Brook et al., 2010; Fuks et al., 2017). Consequently, there is an urgent need to monitor the environmental condition of cities, especially the high traffic congestion areas, where there is increased air pollution, and therefore health risks (Park, 2020; Shekarrizfard et al., 2020; Wan et al., 2020). Due to the emerging importance of ensuring both human and ecosystems' health, several environmental monitoring systems have been implemented across the globe, and various research works have been conducted over the last decades regarding this specific subject (Andersson et al., 2020; Tezel et al., 2019). These systems constitute a useful tool to provide real-time monitoring of environmental health conditions and help to prevent serious problems. Besides, they are a handy tool for delivering valuable data that can be utilized to measure various specific indexes and evaluate the effectiveness of measures regarding sustainable mobility, such as those implemented in the CIVITAS DESTINATIONS initiative (Tournaki et al., 2017, 2018).

To overcome the problems mentioned above and achieve a balanced low-carbon economy by 2050, Europe is seeking to change the need to reduce transport pollution by at least $60 \%$ relative to 1990 . The incremental shift away from fossil fuel-based transport systems and the adoption of new and innovative low-carbon solutions was already an objective in the Transport White Paper of 2011. It was outlined in various 
policy documents (European Commission, 2003, 2017). In particular, some of the measures taken are to reduce the speed limit within cities to force citizens to make more use of public transport. Moreover, a more successful approach will be to outlaw the most polluting cars and place substantial penalties on offenders. Therefore, a monitoring scheme for air emissions, car traffic control, and air quality documentation is required to allow proper use of these data and improve the situation. A noteworthy alternative regarding sustainable mobility is the use of alternative fuels, such as biodiesel, in some cases with several significant advantages and weaknesses (Foteinis et al., 2018; Tsoutsos et al., 2010, 2019). An additional alternative that enhances the sustainable mobility concept refers to the use of Electric Vehicles (EVs) or HydrogenElectric Vehicles (HEVs), which both seem to play a vital and determinant role in the future of the transportation sector (Pavić et al., 2020; Smaragdakis et al., 2020).

Six European island cities, attracting a high number of tourists from Europe and worldwide, are implementing sustainable mobility measures within the Horizon 2020 CIVITAS DESTINATIONS project; Funchal (Madeira-Portugal), Las Palmas de Gran Canaria (Spain), Elba (Italy), Valletta (Malta), Limassol (Cyprus), and Rethymno (Crete-Greece). A refined Impact Assessment Framework has been developed, which includes a set of indicators to estimate the environmental benefits in transport, economy, society, energy, and the environment, due to the DESTINATIONS measures. This assessment methodology is based on the guidelines of CIVITAS SATELLITE, adapted to project objectives and specific insular conditions, with the addition of new indicators in terms of pollution and energy (Tournaki et al., 2017, 2018). In this book chapter, the two representative environmental monitoring cases in Madeira and Rethymno are introduced to strengthen the mobility policy and preparation.

After the introductory section, a thorough insight of the two environmental monitoring systems is presented, and at last, the conclusions regarding the effectiveness and the applicability of these two systems are being evaluated and demonstrated.

\section{A Detailed Description of the Two Systems}

\subsection{The Case of Rethymno}

A methodology was developed and applied in Rethymno under the CIVITAS DESTINATIONS initiative, which continuously monitors the acquired data during different annual periods, integrating the seasonal fluctuation due to tourism, outdoor activities, and festivals (highly crowded events). 


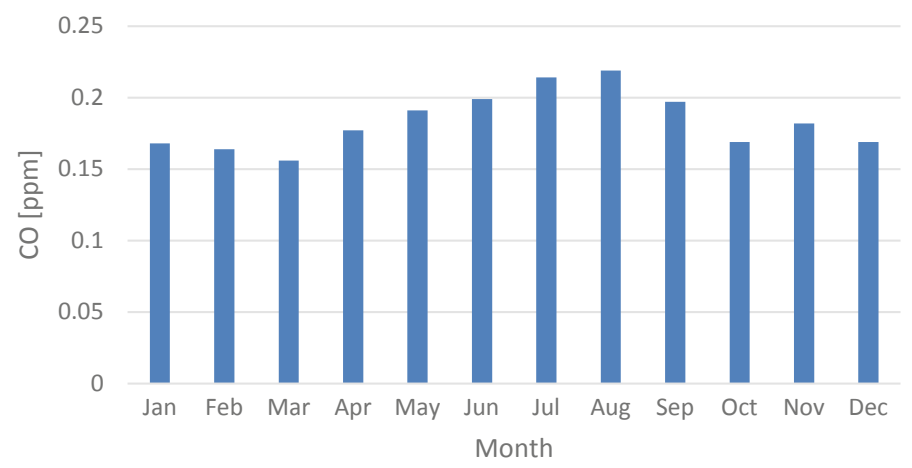

Fig. 1 Seasonal fluctuation of $\mathrm{CO}$ for the city of Rethymno

\subsubsection{Overview of the Area of Study (Rethymno)}

Rethymno is the third biggest city in the island of Crete, with a total area of 397.48 $\mathrm{km}^{2}$, and a total population of 63,000 inhabitants. Indicatively, it has been calculated that the index describing the number of vehicles per 1,000 residents equals 533, which means that at least every household in the city owns a vehicle. The town, on the contrary, does only have a port that serves one or two times a week, during summer months, some itineraries to other Greek islands. The main airports of the island are located in Heraklion (73\% of total arrivals) and Chania (27\% of total arrivals). The main entrances for the city are the island's highway 90 and its port.

Almost 520,000 tourists yearly are being accommodated in municipality's hotels, and it is estimated that more than $30 \%$ of these tourists are staying in suburbs, being served by the city's Public Transport (PT)/mobility services, and more than 1.5 million tourists visit the city on day tours and cruises per year. Besides, let alone the permanent residents of the island, during summer months, the environmental condition of the town is considerably burdened by tourism, and the seasonality fluctuation is very intense. Consequently, the data acquired from the implemented systems evaluate and examine the influence of the flux of tourism. Indicatively, the seasonal fluctuation of CO is depicted in Fig. 1.

\subsubsection{Insight in the Pilot Environmental Monitoring System}

\section{Overview}

The monitoring system in Rethymno, developed by the Renewable and Sustainable Energy Systems Lab of the Technical University of Crete (ReSEL-TUC), is a low-cost environmental monitoring equipment designed as a part of the CIVITAS DESTINATIONS project. The system employs a two-level scheme, at pedestrian and building level, shaping a two-level monitoring system, recording and comparing 
pollutant concentrations during rush hours. Three meteorological stations, with integrated environmental monitoring sensors, are installed on buildings within the city, conducting measurements of air pollutant concentrations, noise level, ambient air temperature, humidity levels, and wind speed on a 5-min interval. The recorded measurements are stored in a database. They can be presented online in real-time via webpage with a modification on the software algorithm and the installation of a SIM card on the $3 \mathrm{G}$ modem of the device. The above stations are non-intrusive (above ground) and consist of: (a) support base, (b) specially designed housing, (c) integrated sensors, and (d) a recording unit and data storage and transmitting software.

The sensors, as well as the unit for recording and sending data, are integrated into a standard shell that is compact and made of such materials to ensure both protection from external weather conditions and its smooth operation throughout the lifetime of the system. The sensors were selected and appropriately integrated into the system so that the software can detect each pollutant individually, and a cross-sensitivity case is excluded. Each measurement is unique and captured as accurately as possible in the actual situation. For data collection, the sensors function as stand-alone systems and are connected through the unique software to the host computer, where the data is recorded, and stored.

\section{Technical specifications}

The environmental station is an autonomous, fixed mounting air quality monitoring station that tracks the key air pollutants and weather parameters. The equipment is placed into urban areas of cities to collect localized data for air pollution, noise pollution, and microclimate conditions. The sensors and the electronic circuits are protected against the weather using an industrial enclosure with column mounting support. The data are stored into the included microSD card. They can be transferred in real time via the GPRS network to the cloud to be stored and used for the depiction of the environmental conditions all over the city if a SIM card is inserted.

It features a low power and high accuracy real-time clock with a battery-backed based on the DS3231. On the start-up, the station initializes a local Wi-Fi network, which allows the authenticated users to download the historical data directly to their connected devices. Furthermore, the GSM module establishes a connection to the remote server through GPRS and push new data in fixed 5-min intervals using the MQTT protocol. Figure 2 illustrates the hardware architecture of the prototype implementation. The selected MCU includes multiple hardware interfaces capable of maintaining the connection with all sensors and modules simultaneously.

The air pollution measurements are acquired through a high-quality scattering sensor to detect the Particulate Matter PM2.5/PM10 concentration in the air. Additionally, the prototype contains the MiCS-6814, which is a compact Metal Oxide Semiconductor (MOS) sensor with three fully independent sensing elements to measure concentration levels of pollutants such as carbon monoxide; nitrogen dioxide, and ammonia. This configuration includes a high-precision non-dispersive infrared sensor to measure the concentration levels of carbon dioxide in the air. The technical specifications of the air pollution sensors are presented in Table 1. 


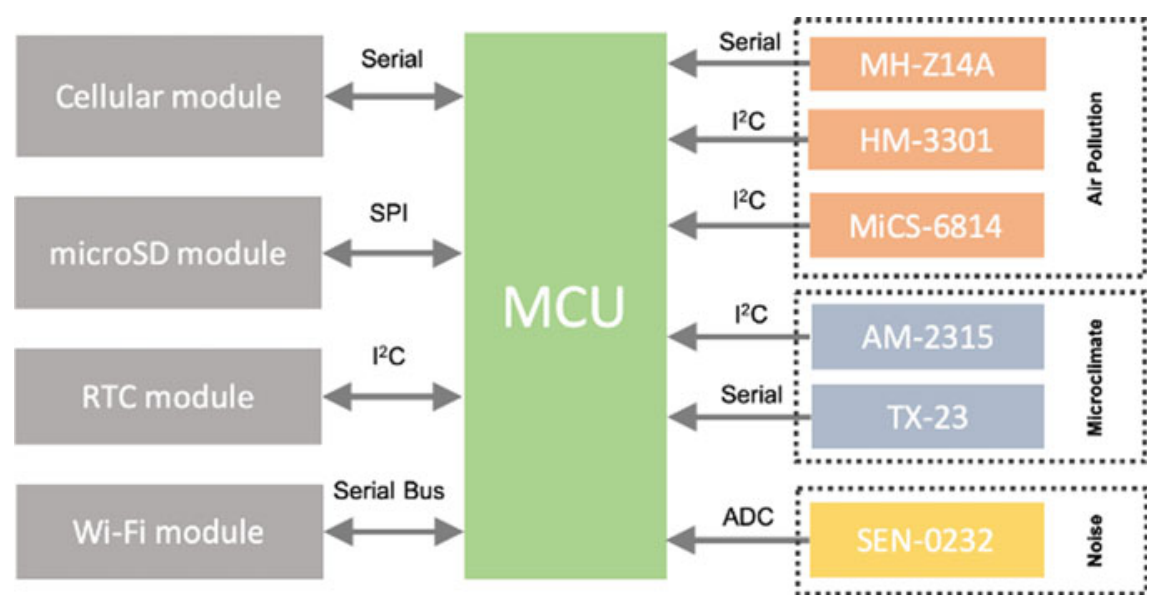

Fig. 2 Hardware architecture and interfaces

Table 1 Technical specifications of air pollution sensors

\begin{tabular}{l|l|l|l|l|l}
\hline Sensor & Parameter & Range & Resolution & Accuracy & Lifespan \\
\hline \multirow{2}{*}{ MiCS-6814 } & $\mathrm{CO}$ & 0 to $1000 \mathrm{ppm}$ & $0.1 \mathrm{ppm}$ & $0.5 \mathrm{ppm}$ & $>5$ years \\
\cline { 2 - 6 } & $\mathrm{NO}_{2}$ & 0 to $10 \mathrm{ppm}$ & $20 \mathrm{ppb}$ & $5 \%$ & $>5$ years \\
\cline { 2 - 6 } & $\mathrm{H}_{2}$ & 0 to $1000 \mathrm{ppm}$ & $1 \mathrm{ppm}$ & $5 \%$ & $>5$ years \\
\cline { 2 - 6 } & $\mathrm{NH}_{3}$ & 1 to $500 \mathrm{ppm}$ & $1 \mathrm{ppm}$ & $5 \%$ & $>5$ years \\
\cline { 2 - 6 } & $\mathrm{C}_{2} \mathrm{H}_{5} \mathrm{OH}$ & 0 to $500 \mathrm{ppm}$ & $1 \mathrm{ppm}$ & $5 \%$ & $>5$ years \\
\hline MH-Z14A & $\mathrm{CO}_{2}$ & 0 to $5000 \mathrm{ppm}$ & $50 \mathrm{ppm}$ & $3 \%$ & $>3$ years \\
\hline $\mathrm{HM} 3301$ & Particle matter & 1 to $500 \mathrm{ug} / \mathrm{m}^{3}$ & $1 \mathrm{ug} / \mathrm{m}^{3}$ & $5 \%$ & $>2$ years \\
\hline
\end{tabular}

For the microclimate measurements, the AM-2315 digital temperature and humidity sensors are used. On the top of the enclosure is placed a TECHNOLINE TX 23 wind sensor capable of measuring high wind speeds up to $180 \mathrm{~km} / \mathrm{h}$. Furthermore, this sensor includes a wind direction sensor with a high-resolution digital decoder. The technical specifications of the microclimate sensors are presented in Table 2.

Furthermore, for the noise pollution, an instrument circuit and low noise microphone to accurately measure the sound level of the surrounding environment are

Table 2 Technical specifications of the microclimate sensors

\begin{tabular}{l|l|l|l|l|l}
\hline Sensor & Parameter & Range & Resolution & Accuracy & Lifespan \\
\hline \multirow{2}{*}{ AM-2315 } & Temperature & -20 to $80{ }^{\circ} \mathrm{C}$ & $0.1^{\circ} \mathrm{C}$ & $0.1^{\circ} \mathrm{C}$ & $>10$ years \\
\cline { 2 - 6 } & Relative humidity & 0 to $100 \%$ & $1 \%$ & $2 \%$ & $>10$ years \\
\hline \multirow{2}{*}{ TX-23 } & Wind speed & 0 to $50 \mathrm{~m} / \mathrm{s}$ & $0.1 \mathrm{~m} / \mathrm{s}$ & $0.9 \mathrm{~m} / \mathrm{s}$ & $>10$ years \\
\cline { 2 - 6 } & Wind direction & 0 to $360^{\circ}$ & $22.5^{\circ}$ & $22.5^{\circ}$ & $>10$ years \\
\hline
\end{tabular}


featured. This circuit provides linearity between the output voltage and the decibel value, which leads to a simple conversion equation avoiding the logarithmic computations in the Micro-Controller Unit (MCU). The technical specifications of the noise sensors are presented in Table 3 .

Lastly, the general technical specifications of the installed stations are presented in Table 4.

Table 3 Technical specifications of the noise sensor

\begin{tabular}{l|l|l|l|l|l}
\hline Sensor & Parameter & Range & Resolution & Accuracy & Life span \\
\hline SEN-0232 & Sound/Noise & 30 to $130 \mathrm{~dB}$ & $1 \mathrm{~dB}$ & $1.5 \mathrm{~dB}$ & $>10$ years \\
\hline
\end{tabular}

Table 4 General technical specifications of the stations

\begin{tabular}{l|l|l}
\hline Category & Parameter & Value \\
\hline \multirow{4}{*}{ General } & Dimensions & $\begin{array}{l}135 \times 170 \times 441 \\
\mathrm{~mm}\end{array}$ \\
\cline { 2 - 3 } & Weight & $1.7 \mathrm{~kg}$ \\
\cline { 2 - 3 } & $\begin{array}{l}\text { Power supply cable } \\
\text { length }\end{array}$ & $10 \mathrm{~m}$ \\
\cline { 2 - 3 } & Color & Light grey \\
\hline Power supply & A/C input & $\begin{array}{l}240 \mathrm{VC}, 50 / 60 \mathrm{~Hz}, \\
5 \mathrm{~A}\end{array}$ \\
\cline { 2 - 3 } Wireless network & A/C output & $5 \mathrm{~V} \mathrm{DC}, 1 \mathrm{~A}$ \\
\cline { 2 - 3 } & Weather resistance & IP 65 \\
\cline { 2 - 3 } & Plug type & Type F \\
\cline { 2 - 3 } & Standards & Wi-Fi $2.4 \mathrm{GHz}$ \\
\cline { 2 - 3 } & Frequencies & IEEE $802.11 \mathrm{~b} / \mathrm{g} / \mathrm{n}$ \\
\cline { 2 - 3 } & Chip & ESP8266 $2483.5 \mathrm{MHz}$ \\
\cline { 2 - 3 } & Certifications & CE, FCC \\
\hline Internal storage & Connectivity & GPRS over GSM \\
\cline { 2 - 3 } & Frequencies & $\begin{array}{l}850,900,1800, \\
1900 \mathrm{MHz}\end{array}$ \\
\cline { 2 - 3 } & SD card & SIMCom SIM800L \\
\hline & Chip & $\begin{array}{l}\text { CE, GCF, FCC, TA, } \\
\text { CTA, RoHS }\end{array}$ \\
\cline { 2 - 3 } & Certifications & FAT32 \\
\hline & &
\end{tabular}




\subsubsection{Exact Siting (Sites) of the Implemented Systems}

The representatives for the city measurement locations were selected based on the open discussion with all the city's policy-making actors (municipality, tourism office, chamber of commerce, technical chamber, associations of citizens). The three meteorological stations, alongside with eleven thermocameras, are located in critical city points that present high traffic activity. Regarding the meteorological stations, they are equipped with durable sensors in building level height, to avoid missing data and damages. The exact location of each station is depicted in Fig. 3.

Stations 01, 03, and camera 05 are located next to the sea in the regional road of Rethymno near Fortezza Castle, where a significant number of cars are passing by each day, particularly during the summer months because of the attractiveness of the landmark. Station 03 and camera 06 are located in the south entrance to the city of Rethymno for passengers who are coming through highway 90 . Besides, a market is set up every Tuesday near this site, and increased traffic load is observed during the operation hours. These two options are selected because there are both thermocameras and meteorological stations in these sites. Consequently, correlations between traffic (vehicle count) and several atmospheric pollutants can be drawn.

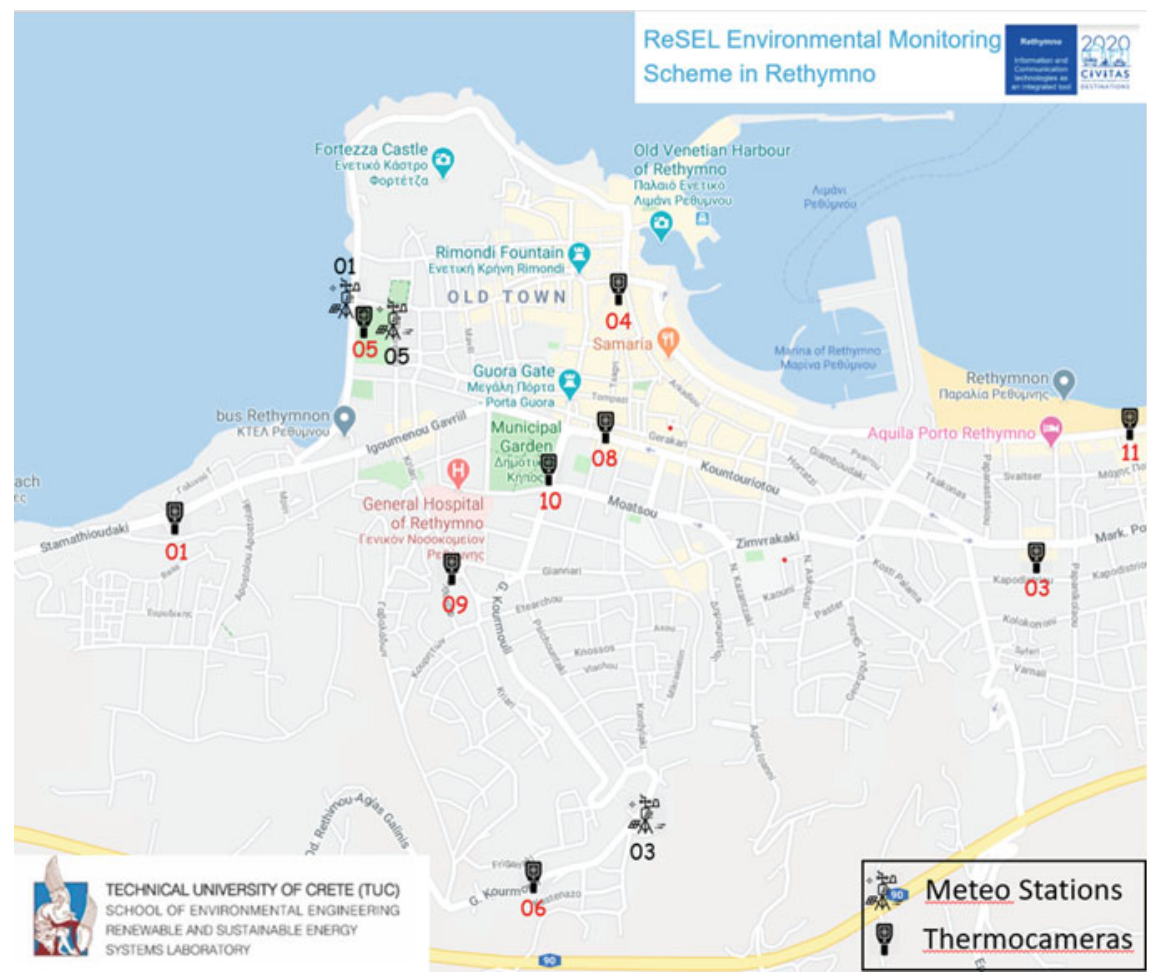

Fig. 3 Meteo stations and thermocameras sites 


\subsubsection{Indicative Outcomes of the Data Deriving from the System}

The measurements are taken in fixed 5-min intervals. The data are accessible remotely using an API interface or directly through the local Wi-Fi network of the device. The purpose of this prototype implementation is to establish a global network of monitoring stations in the urban areas focused on continuous environmental observations. Combining the different connectivity options and low power consumption, this solution can be deployed for a large variety of field applications. The router has, after all, packages installed, adequate storage to save more than two years of data. In addition, the data is received by the Wi-Fi device or is sent to a central server in a proper format that can be easily analyzed by the receiver. Figure 4 depicts an example of the visualization of the data.

Due to the operation of the environmental monitoring stations and the acquired measurements, several conclusions regarding the seasonality of the environmental condition of the city can be drawn, such as that the concentration of $\mathrm{CO}_{2}$ in the city is higher during winter months than during summer months. Many may argue with this due to the increased tourism factor. However, there is strong evidence that the use of heating equipment mainly causes this seasonality during winter, which emits a lot more $\mathrm{CO}_{2}$ than cars and generally tourism activity. The aforementioned can be observed in Fig. 5, which depicts the daily mean concentration of $\mathrm{CO}_{2}$, for both winter and summer.

By taking advantage of the acquired data from the thermocameras alongside the data of the environmental monitoring stations, there is an excellent bunch of correlations that can be made, and several conclusions can be drawn. Indicatively, the

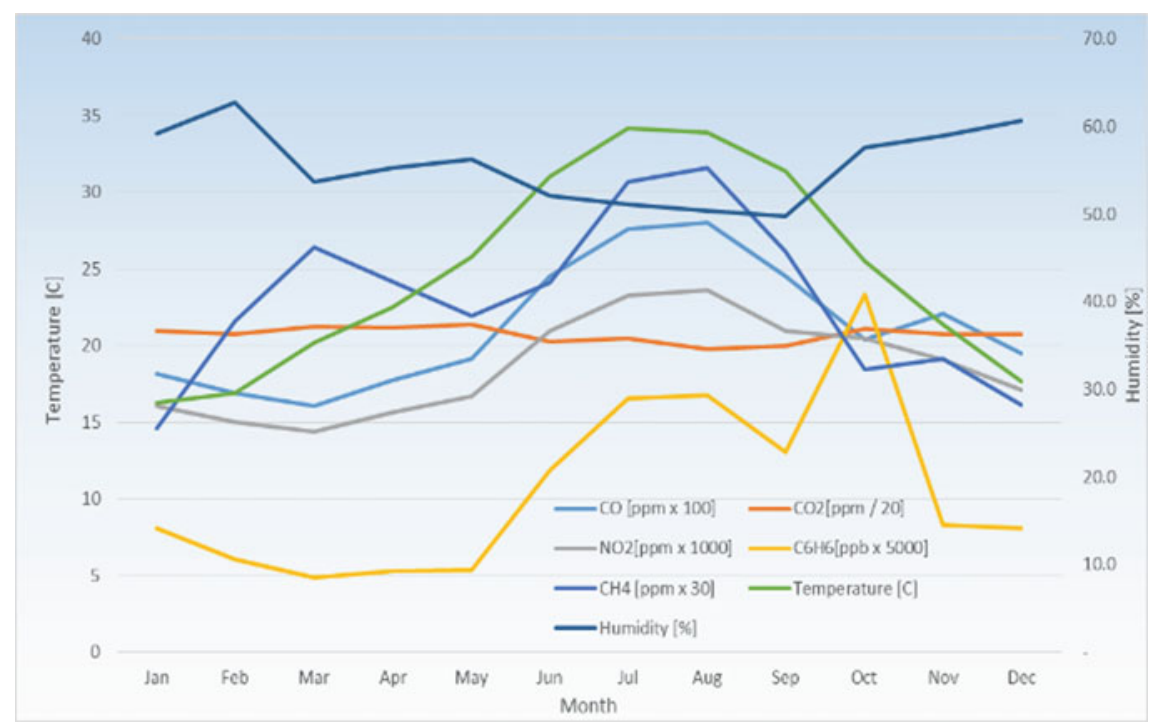

Fig. 4 Monthly data of air measurements 


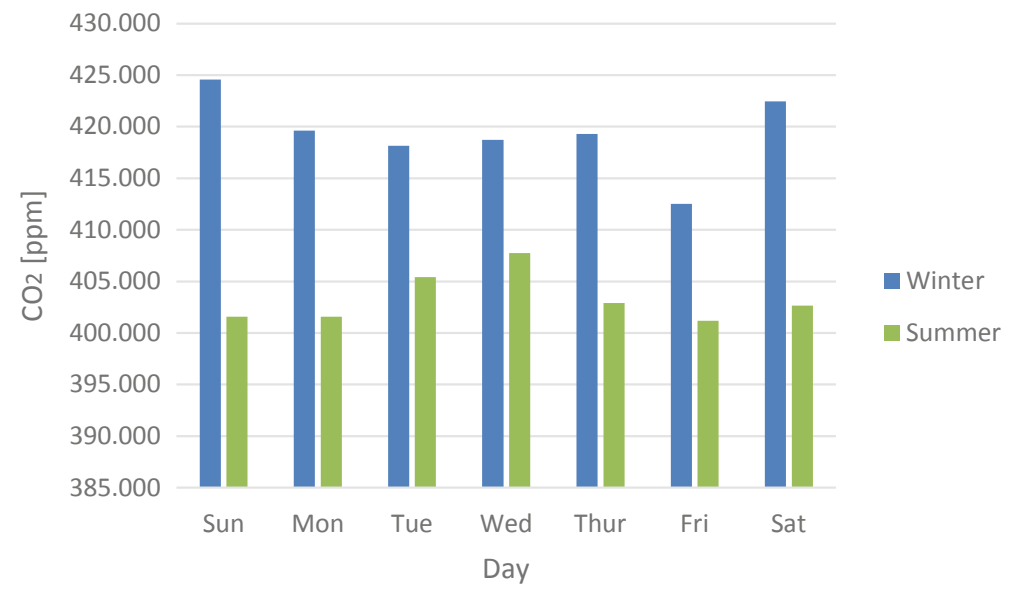

Fig. 5 Mean daily $\mathrm{CO}_{2}$ concentration among the two seasons

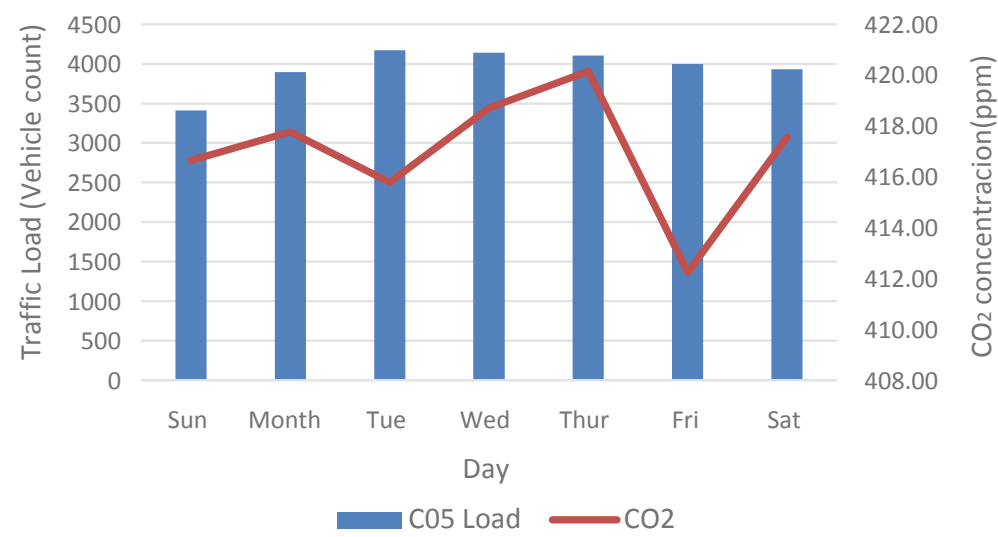

Fig. 6 Correlation between $\mathrm{CO}_{2}$ concentration and traffic load

mean daily values of $\mathrm{CO}_{2}$ in conjunction with the number of vehicles, for a period of measurements, are presented in Fig. 6.

\subsection{The Case of Madeira}

In the island of Madeira, Regional Agency for Research, Technological Development and Innovation (ARDITI) has designed and developed a low-cost Internet of Things (IoT)-based environmental monitoring station with integrated sensors for 
real-time measurement of $\mathrm{CO}_{2}, \mathrm{CO}, \mathrm{NO}_{2}, \mathrm{O}_{3}, \mathrm{SO}_{2}, \mathrm{NO}, \mathrm{PM} 2.5 / \mathrm{PM} 10$, noise, temperature, humidity, and atmospheric pressure. The smart system is installed in eight urban locations in the city of Funchal in order to collect data related to transport load and the environmental conditions in the whole city. Three such stations are located in key entry spots in Funchal where the municipality also installed a traffic counting/monitoring system.

Gathered data can then be related to urban accessibility, traffic and environmental indicators, and users satisfaction. It makes use of smart, low-cost solutions, based on wireless networks and crowd-sourced data. The Environmental Monitoring Station presented here is one of the results of ARDITI work in CIVITAS DESTINATIONS project.

\subsubsection{Hardware Overview}

The sensors were selected based on their quality, cost, availability, and openness (to external hardware and software connection). Subsequently, the software was developed (mainly in Python) and the sensors were connected to the central unit (a smart router/embedded computer), which in the current version is the GL-AR300M Mini Smart Router, from GL-iNet manufacturer. Sensor control, reading, and communication software is installed and configured in the local embedded computer which runs the necessary software to control the sensors, measure indicators, and communicate with the server database. With the intent to make the system modular, we chose sensors that have a USB interface, or that could be read through intermediate hardware (see Table 5). We use a USB hub to accommodate the sensors required for each location, connected with the embedded system (in our case, using a router, we exploit its connectivity features to access real-time sensing data). The sensors that

Table 5 Technical specifications of sensors used (ARDITI, 2019)

\begin{tabular}{l|l|l}
\hline Reading/Indicator & Sensor used & Output/Interface \\
\hline Particles $(\mathrm{PM} 2.5, \mathrm{PM} 10)$ & Nova PM sensor SDS011 & USB \\
\hline Ozone $\left(\mathrm{O}_{3}\right)$ & Sensoric O3 3E 1 & $4-20 \mathrm{~mA}$ \\
\hline Carbon Dioxide $\left(\mathrm{CO}_{2}\right)$ & Yocto-CO & USB \\
\hline Sulfur Dioxide $\left(\mathrm{SO}_{2}\right)$ & $\mathrm{SO}_{2} \mathrm{SL} 4-20 \mathrm{~mA}$ Transmitter & $4-20 \mathrm{~mA}$ \\
\hline Nitrogen Dioxide $\left(\mathrm{NO}_{2}\right)$ & $\begin{array}{l}\mathrm{NO}_{2} 2 \mathrm{E} \text { sensor with 4-20 mA } \\
\text { transmitter, 0-20 ppm }\end{array}$ & $4-20 \mathrm{~mA}$ \\
\hline $\mathrm{CO}$ & $\begin{array}{l}\text { CO ECO-Sure }(2 \mathrm{e}) \text { 4-20 mA } \\
\text { Transmitter }\end{array}$ & $4-20 \mathrm{~mA}$ \\
\hline Nitrogen Oxide $(\mathrm{NO})$ & 4-NO-2000 & $0-5 \mathrm{~V}$ \\
\hline Temperature, humidity, air pressure & Yocto-Meteo & USB \\
\hline Noise & $\begin{array}{l}\text { Digital microphone with } \\
\text { integrated sound card }\end{array}$ & USB \\
\hline
\end{tabular}


have output in the current (mA) or voltage (V) are read by USB current and voltage sensors from Yoctopuce (Yocto-4-20mARx and Yocto-0-10 V-Rx).

\subsubsection{Software Overview}

The access to the embed system is done remotely, to transfer files and run system commands. The software to read the sensors (sensor poller) is in the embedded system and is responsible for capturing the data points and send them to a central server employing a network connection. The system is composed of a capturing component, an upload manager, and a data sender. The capturing component interacts with the different modules that acquire the data and forwards it to the upload manager. The upload manager checks the server connectivity and either sends the current and saved data, or stores it locally when no connection is found. The upload manager passes the data to the data sender, which authenticates the requests and actually sends them to the central server. The VPN connection can be used to remotely control the system and perform maintenance, or software upgrades, access the embed system, to transfer files and/or run system commands. Figure 7 illustrates the software architecture implemented.

The modular platform has been designed so as to integrate different sensors in order to satisfy the requirements of each city and also to accommodate different methods of data communication, ranging from the cabled network, Wi-Fi, USB 3G modem, or the possibility of LoRa (see Fig. 8). This gives the possibility for each location to have specific characteristics, where the number of sensors integrated into the device and the communication method can be selected/decided for each location.

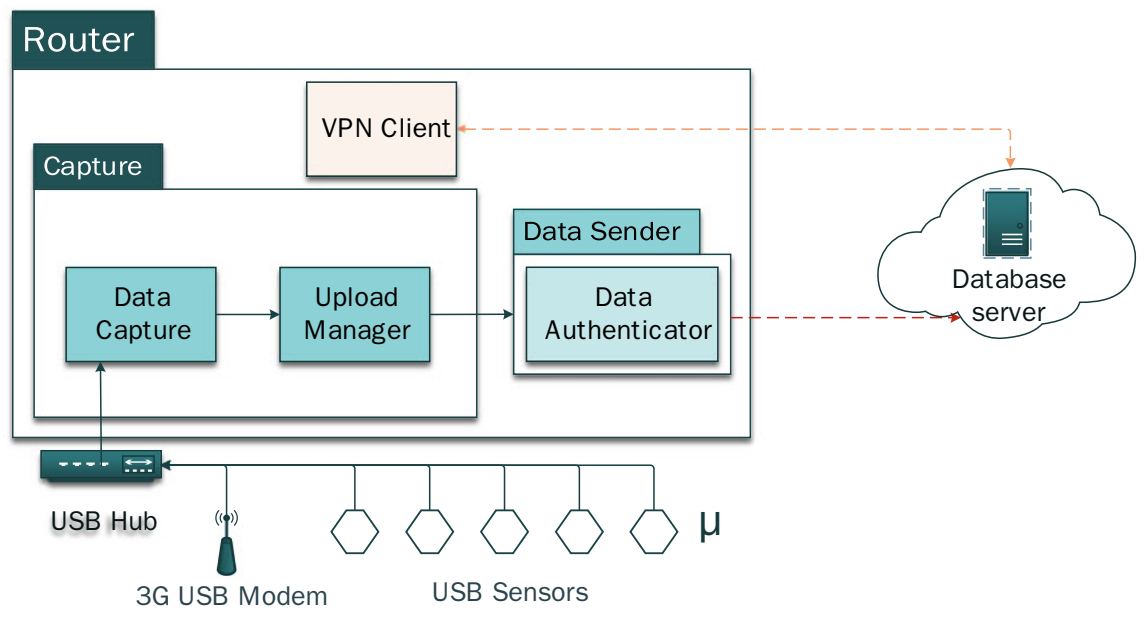

Fig. 7 Software architecture overview (ARDITI, 2019) 


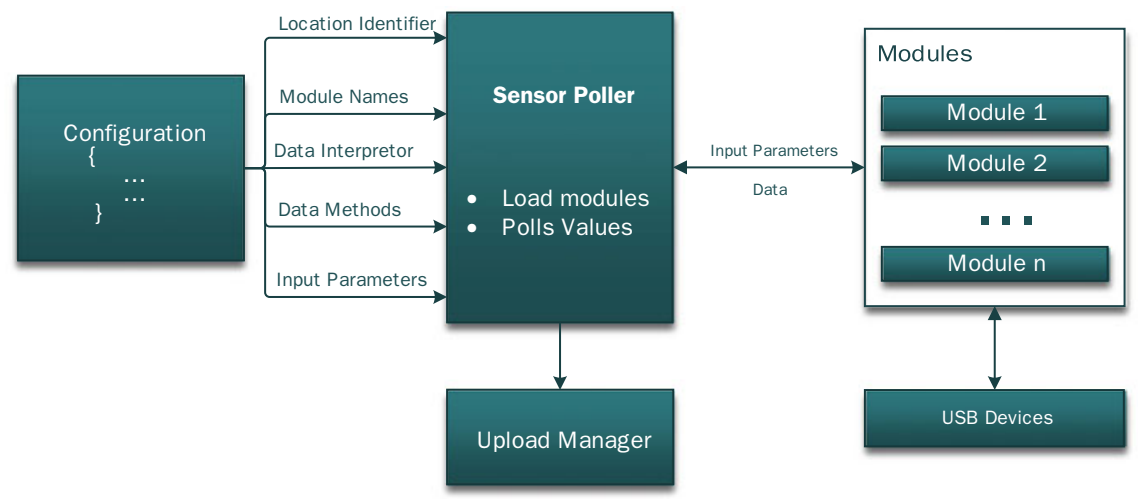

Fig. 8 Sensor poller overview

The collected data are presented in a real-time web page and stored in a central database for monitoring and historical recording. The overall infrastructure/system represents a smart, low-cost alternative solution for environmental monitoring, based on wireless networks and crowd-sourced data. If compared to existing commercial solutions, this solution offers a low-cost alternative to cities for air quality/noise monitoring. It can easily be adapted/customized for different scenarios. 3D model files for the casing have been created in open Drawing Interchange Format (DXF).

\subsubsection{Prototype}

With the interconnected sensors encased in a box to accommodate all the components and sensors, the boxes are not waterproof, due to the need of the exposure of the sensors to the outside air, thus needing protection shields as shown in Fig. 9. The protection is attached to the box and attached to a supporting mount. Three housing prototypes have been created and tested: one of such prototypes was used as the base to estimate the right dimensions and compartments of the final version of the
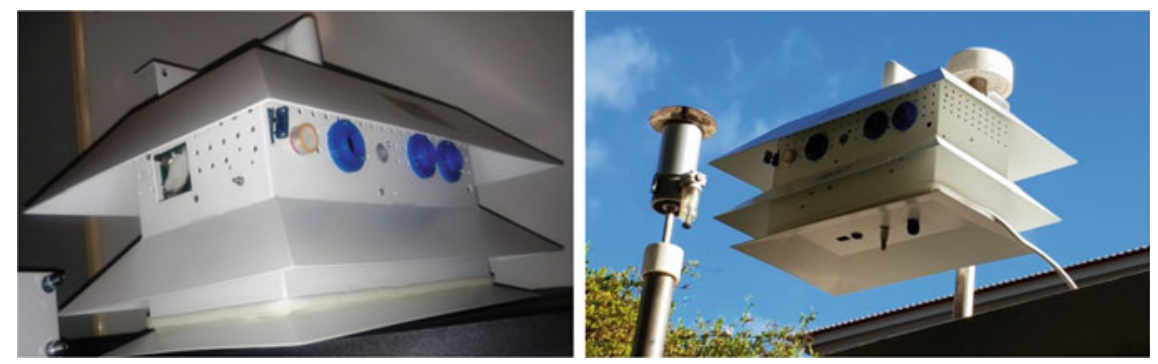

Fig. 9 Sensors and housing in the final prototype 
box/housing. Then, using our 3D (DXF) model files, construction of the housing was made in "carbon steel" by a subcontracted provider.

\subsubsection{Connection Scheme}

The modular platform has been designed so as to integrate different sensors in order to satisfy the requirements of each city. This gives the possibility for each location to have specific characteristics, where the number of sensors integrated into the device can be selected/decided by each city. As presented in Fig. 10 some sensors provide a direct reading via USB while others require either a voltage or a current intermediate reader. A USB hub provides all the USB ports needed by the system, including connection to a $3 \mathrm{G}$ Modem in case Wi-Fi Internet is not available to the router (e.g., in remote zones). The only particular case to note is the NO sensor, which requires a voltage reader and power supply of $5 \mathrm{~V}$. To achieve this, a DC/DC converter connected to the $23 \mathrm{~V}$ output of the voltage reader was used. Then an amplifier (OpAmp) was used to maintain the output signal readable. Figure 11 presents the connectors inside the housing/box and how it is all assembled in the final prototype.

Not considering human resources costs, 3,000€ was the estimated cost to purchase and assemble components, produce the custom case and assemble the current prototype of the station (concrete installations may incur in additional costs). The total monitoring system has been developed in order to be a transferable solution to support green mobility and have replicability potential; it is a low-cost solution, can be adopted and installed at any city, while ARDITI can provide the necessary support for installation (the list of components/sensors, 3D model files for the protective casing in DXF format and the software that needs to be installed in the embedded system, api, database, and data visualization).

\subsubsection{Deployment}

The sensor stations were installed in 8 urban locations in the city of Funchal, with three such stations located in key entry spots in Funchal where the municipality also installed a traffic counting/monitoring system. Figure 12 shows the location of the sensors throughout the city.

The data captured, if stored locally, can be retrieved via SFTP with a capacity for approximately 4 months of local data storage. If the data is sent to a central server, the API that receives it, can also provide API endpoints to visualize it, as is the case of the one implemented by ARDITI, where the data can be accessed via a web platform that accesses the API and displays the real-time data (Fig. 13).

The collection of critical and reliable data can lead to an adequate evaluation of the overall performance of implemented measures, toward sustainable, environmentally friendly and low-carbon mobility policies. The environmental monitoring schemes presented in this work can provide an efficient, reliable, replicable, low-cost, continuous view and data of the urban environment, allowing urban planners and authorities 


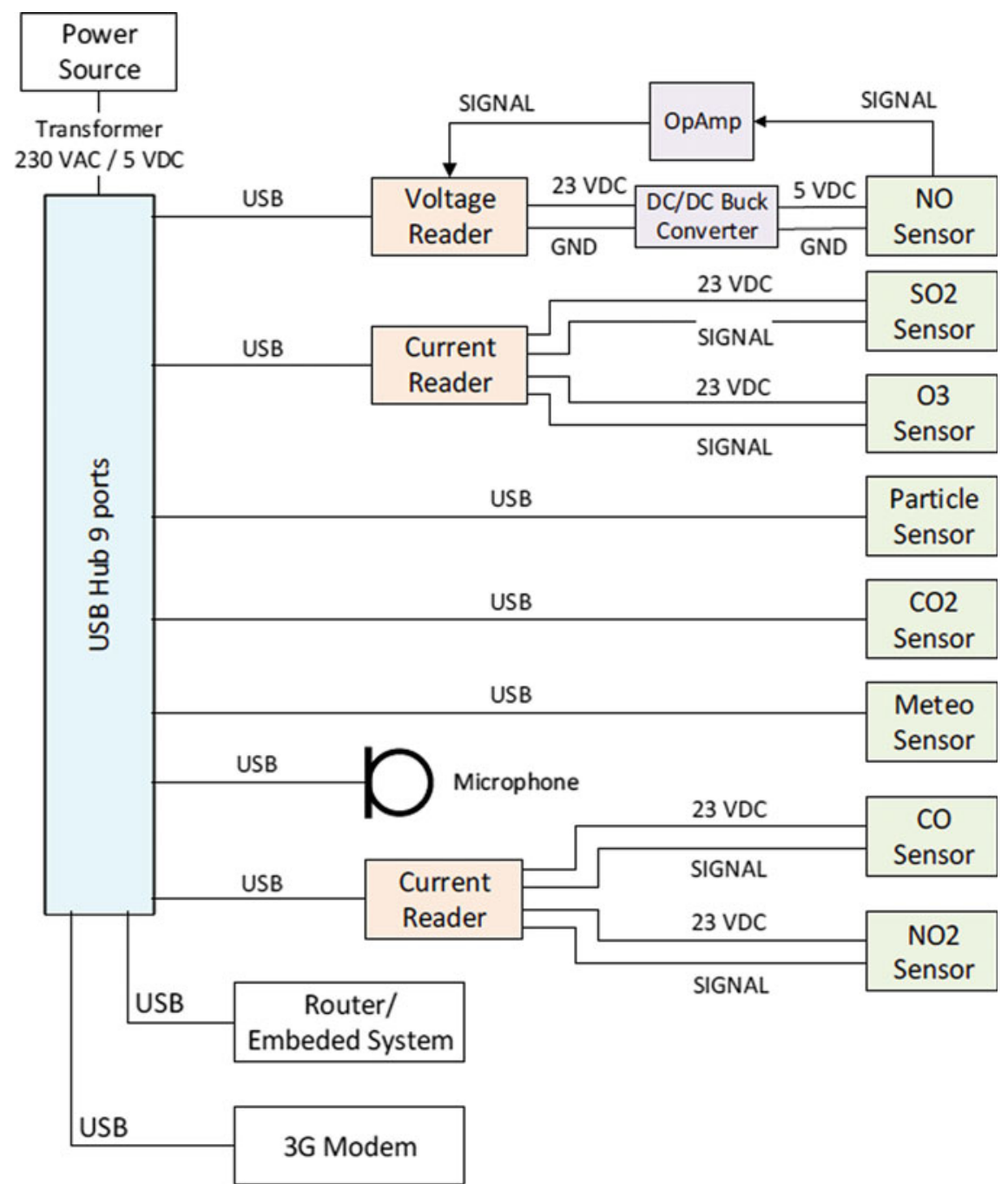

Fig. 10 Sensor connection scheme

to locate traffic congestion points and analyze the environmental impact of transportation; therefore, to adapt their mobility strategies and to formulate suitable sustainable mobility solutions if/when/where needed.

It is worth to notice that the authorities remain in charge to implement sustainable strategies and take decisions, but tools like these can support decision-making as they provide an easy way to visualize and detect relevant/not usual situations and to enhance awareness, supporting and facilitating the communication between the different community's needs. In fact, sustainable development requires to join the 


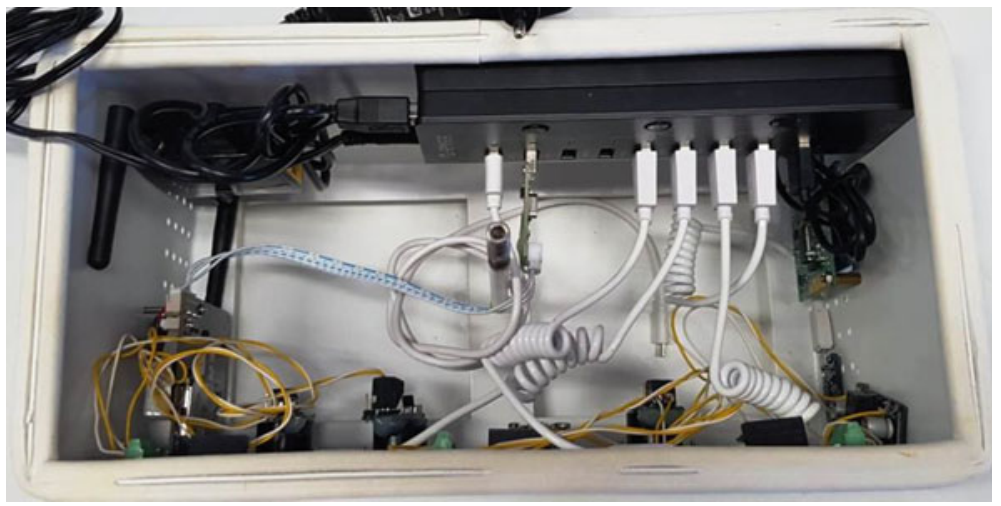

Fig. 11 Sensors, smart router and connectors

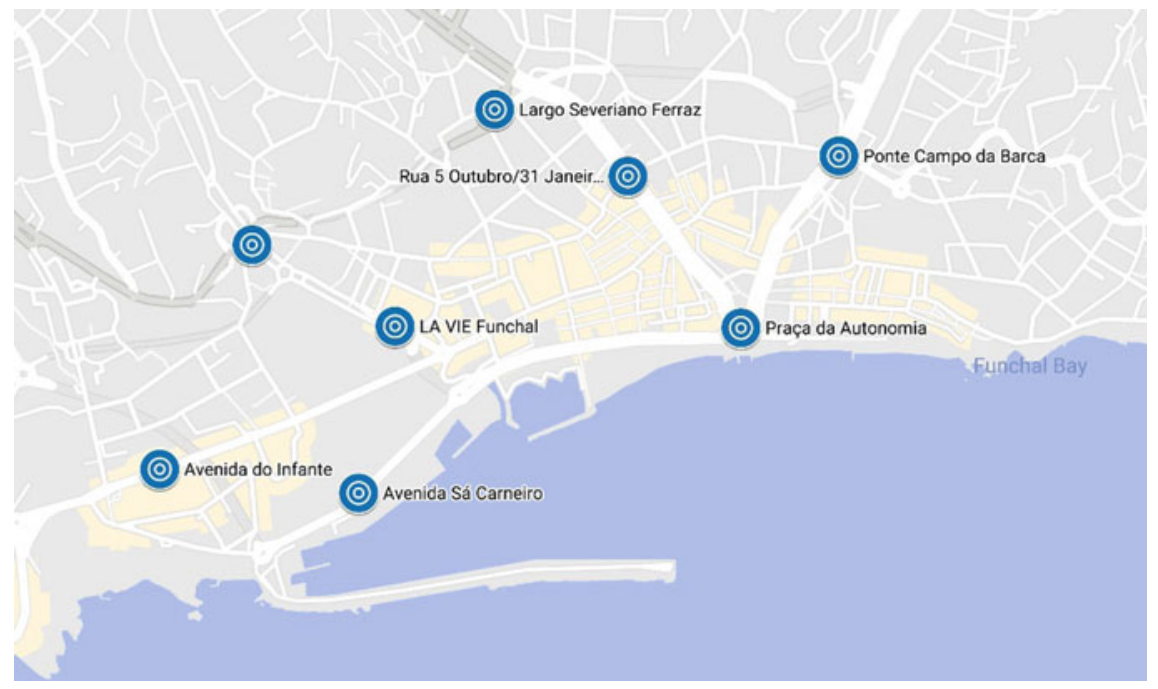

Fig. 12 Sensor map in the city of Funchal

effort of the different communities and authorities, to consider its social dimension, and to become an effective framework to improve sustainable mobility and tourism.

The collected sensing data can be put to good use to improve the daily mobility experience, employing sustainable mobility by monitoring its effects in the air quality of the cities. Moreover, this solution represents an opportunity to investigate the possibility to meet the different needs, by providing environmental-related information not only to the official entities, but also empowering the different communities, by collaborating in the sustainable development. To promote this idea, we plan to evolve our platform into a full community network capable of offering other personalized 


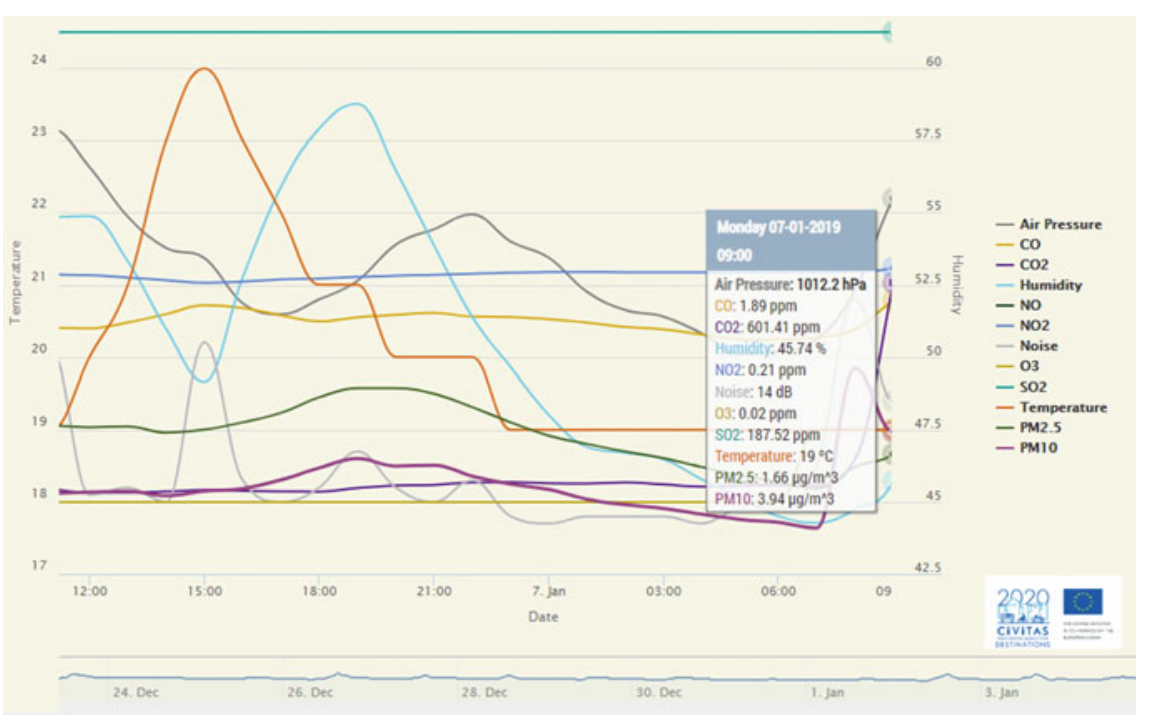

Fig. 13 Real-time sensor data visualization

services to communities, exploring crowdsourcing and crowdsensing where citizens can acquire their own open-source stations and contribute to the network.

\section{Conclusions and Recommendations for Future Research}

In this chapter, two novel low-cost IoT environmental monitoring systems were demonstrated for the evaluation of the environmental condition of two European cities, which have in common that during summer months, there is high touristic demand. Therefore, the air pollutants' levels are supposed to skyrocket. After the preliminary analysis of the acquired data, it was proven that this assumption is false, as the environmental condition of the cities seems to worsen, but still, the pollutants' concentrations do not increase that much to override the legislation limits and become dangerous for human health.

It is also shown that such systems can be an excellent evaluation tool for any sustainability measure in the vital aspect of environmental quality and air pollution, and therefore human and ecosystem's health. Rethymno is proven to be a pollutionfree city even on periods of peak demand when the traffic congestion in the central city's streets is high, and the GHGs from the vehicles are increased. Even in periods where festivals and other highly crowded events take place, the city remains in average levels of air pollution, exhibiting some momentary measurements out of legislative limits. 
Consequently, the stations have proven to be an essential tool for any research team, and mainly for the urban planners and authorities, as they offer the capability of monitoring traffic congestion points and their impact on the environmental condition. The monitoring systems and the data can be representative of not only the specific location of the stations but for the whole city, as well due to the dispersion of air pollutants.

Lastly, even if these two systems are proven to be a reliable and essential tool for the interested parties, there are many improvements that can be made to increase their applicability and the precision of their measurements. As for the case of the environmental monitoring system of Rethymno, there are some recommendations for the future that aim to the incremental improvement of the stations and are deriving from some problems that have risen up by experiencing their operation for more than two years. So, the recommendations are summarized as follows:

- Energy storage (battery) of at least $1 \mathrm{~h}$ of autonomy should be integrated into the stations in case of power outages;

- If more precision on measurements is desired, new innovative sensors can replace the old ones with the consequence of extra cost;

- The software's algorithm should be updated with a newly created script that could easily depict the measurements in easily comprehensible figures that will be easy to import in any of the authorities' website;

- Better wind and dust sensors should replace the already integrated due to their complex operation.

\section{References}

Andersson, E. M., Ögren, M., Molnár, P., et al. (2020). Road traffic noise, air pollution and cardiovascular events in a Swedish cohort. Environmental Research, 185, 109446. https://doi.org/10. 1016/j.envres.2020.109446

Andrés, L., \& Padilla, E. (2018). Driving factors of GHG emissions in the EU transport activity. Transport Policy, 61, 60-74. https://doi.org/10.1016/j.tranpol.2017.10.008

Bharadwaj, S., Ballare, S., \& Rohit, C. M. K. (2017). Impact of congestion on greenhouse gas emissions for road transport in Mumbai metropolitan region. Transportation Research Procedia, 25, 3538-3551. https://doi.org/10.1016/j.trpro.2017.05.282

Brook, R. D., Rajagopalan, S., Pope, C. A., et al. (2010). Particulate matter air pollution and cardiovascular disease: An update to the scientific statement from the American heart association. Circulation, 121, 2331-2378. https://doi.org/10.1161/CIR.0b013e3181dbece1

European Commission. (2003). The revised renewable energy directive.

European Commission. (2017). An agenda for a socially fair transition towards clean, competitive and connected mobility for all. Com, 177, 18.

Foteinis, S., Antoniadis-Gavriil, A., \& Tsoutsos, T. (2018). Life cycle assessment of algae-tobiodiesel shallow pond production systems in the Mediterranean: Influence of species, pond type, by(co)-product valorisation and electricity mix. Biofuels, Bioproducts \& Biorefining, 12, 542-558. https://doi.org/10.1002/bbb.1871

Fuks, K. B., Weinmayr, G., Basagaña, X., et al. (2017). Long-term exposure to ambient air pollution and traffic noise and incident hypertension in seven cohorts of the European study of cohorts for air pollution effects (ESCAPE). European Heart Journal, 38, 983-990. https://doi.org/10.1093/ eurheartj/ehw413 
Letnik, T., Marksel, M., Luppino, G., et al. (2018). Review of policies and measures for sustainable and energy efficient urban transport. Energy, 163, 245-257.https://doi.org/10.1016/j.energy.2018. 08.096

Park, Y. M. (2020). Assessing personal exposure to traffic-related air pollution using individual travel-activity diary data and an on-road source air dispersion model. Heal Place, 63, 102351. https://doi.org/10.1016/j.healthplace.2020.102351

Pavić, I., Pandžić, H., \& Capuder, T. (2020). Electric vehicle based smart e-mobility systemDefinition and comparison to the existing concept. Applied Energy, 272, 115153. https://doi.org/ 10.1016/j.apenergy.2020.115153

Santos, G. (2017). Road transport and $\mathrm{CO}_{2}$ emissions: What are the challenges? Transport Policy, 59, 71-74. https://doi.org/10.1016/j.tranpol.2017.06.007

Shekarrizfard, M., Minet, L., Miller, E., et al. (2020). Influence of travel behaviour and daily mobility on exposure to traffic-related air pollution. Environmental Research, 184, 109326. https://doi.org/ 10.1016/j.envres.2020.109326

Smaragdakis, A., Kamenopoulos, S., \& Tsoutsos, T. (2020). How risky is the introduction of fuel cell electric vehicles in a Mediterranean town? International Journal of Hydrogen Energy, 45, 18075-18088. https://doi.org/10.1016/j.ijhydene.2020.04.224

Tezel, M. N., Sari, D., Ozkurt, N., \& Keskin, S. S. (2019). Combined NOx and noise pollution from road traffic in Trabzon, Turkey. Science of the Total Environment, 696, 134044. https://doi.org/ 10.1016/j.scitotenv.2019.134044

Tournaki, S., Farmaki, E., Tsoutsos, T. (2018). Impact assessment of sustainable mobility in touristic cities of Europe: The CIVITAS DESTINATIONS approach on energy, environment and economy. Green Energy Technology 297-309. https://doi.org/10.1007/978-3-319-89845-2_21

Tournaki, S., Farmaki, E., \& Tsoutsos, T. D. (2017). Sustainable mobility solutions and impact assessment in touristic areas in CIVITAS DESTINATIONS project The case of Rethymno.

Tsoutsos, T., Kouloumpis, V., Zafiris, T., \& Foteinis, S. (2010). Life Cycle Assessment for biodiesel production under Greek climate conditions. Journal of Cleaner Production, 18, 328-335. https:// doi.org/10.1016/j.jclepro.2009.11.002

Tsoutsos, T., Tournaki, S., Gkouskos, Z., et al. (2019). Quality characteristics of biodiesel produced from used cooking oil in Southern Europe. ChemEngineering, 3, 19. https://doi.org/10.3390/che mengineering3010019

Wan, Y., Li, Y., Liu, C., \& Li, Z. (2020). Is traffic accident related to air pollution? A case report from an island of Taihu Lake, China. Atmospheric Pollution Research, 11, 1028-1033. https:// doi.org/10.1016/j.apr.2020.02.018

Open Access This chapter is licensed under the terms of the Creative Commons Attribution 4.0 International License (http://creativecommons.org/licenses/by/4.0/), which permits use, sharing, adaptation, distribution and reproduction in any medium or format, as long as you give appropriate credit to the original author(s) and the source, provide a link to the Creative Commons license and indicate if changes were made.

The images or other third party material in this chapter are included in the chapter's Creative Commons license, unless indicated otherwise in a credit line to the material. If material is not included in the chapter's Creative Commons license and your intended use is not permitted by statutory regulation or exceeds the permitted use, you will need to obtain permission directly from the copyright holder.

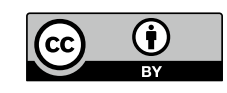

